\title{
Alterações pulpares induzidas pelo tratamento ortodôntico: dogmas e falta de informações
}

\author{
Alberto Consolaro \\ Professor Titular em Patologia Bucal pela Faculdade de Odontologia de Bauru - USP
}

Desde o início da história, junto à ignorância sobre determinado fenômeno ou assunto, há o estabelecimento paralelo de dogmas, mitos, com intermináveis discussões geradoras de medo e limitações, acompanhadas de resignações e sofrimentos. No desenvolvimento da humanidade assim foi, está sendo e será, afinal faz parte da nossa natureza.

O tratamento ortodôntico em adultos felizmente vem aproximando gradativamente a Ortodontia e a Endodontia na prática clínica, mas ainda falta muito para que ambas convivam, compreendendo os fundamentos uma da outra. Percebemos uma amostra da necessidade desta compreensão quando éramos questionados sobre a possibilidade, ou por que a polpa sofreria envelhecimento precoce ou necrosaria durante o tratamento ortodôntico.

Ao consultarmos a literatura, revisando minuciosamente, ano a ano, e por décadas, sobre os efeitos pulpares do tratamento ortodôntico, o espanto foi inevitável.

$\mathrm{Na}$ análise criteriosa de trabalhos não devemos nos levar, logo nos primeiros momentos, por afirmações, opiniões, verificações, descrições e orientações, sem que sejam acompanhadas por dados obtidos por uma metodologia detalhadamente descrita e aplicada em uma amostra suficiente e bem constituída. Na ciência, os dados são mandatórios, enquanto na política e religião predominam a crença e a fé nos argumentos e dogmas.

Antes do planejamento de trabalhos sobre os efeitos pulpares do tratamento ortodôntico analisamos todos, literalmente todos, os trabalhos sobre o assunto e como síntese do observado tem-se:

1) Os designs experimentais para estudos pulpares associados ao movimento ortodôntico usaram diferentes forças e movimentos em espécies variadas e não chegaram a conclusões substantivas.
2) As evidências clínicas demonstravam claramente que o movimento ortodôntico não produz efeitos na polpa e na dentina.

3) As alterações pulpares relatadas após movimentos dentários, inclusive a intrusão, ainda eram especulativas.

Infelizmente, não havia na literatura trabalhos com metodologia adequada, resultados bem analisados e interpretados com conclusões pertinentes sobre o assunto.

Em 2000, orientamos o trabalho de dissertação de mestrado de José Valadares Neto ${ }^{5}$, no qual analisamos microscopicamente o complexo dentinopulpar e as superfícies radiculares externas de dentes humanos de 12 adolescentes, extraídos após a expansão rápida da maxila, comparando-os com dentes de outros três adolescentes sem qualquer movimentação dentária. Quanto ao complexo dentinopulpar concluimos que:

1) Não houve alteração no quadro morfológico quando se avaliou a resposta imediata e após 120 dias de contenção;

2) Não houve alteração no quadro morfológico quando se considerou duas $(0,45 \mathrm{~mm})$ e quatro $(0,9 \mathrm{~mm})$ ativações diárias do parafuso expansor;

3) A expansão rápida da maxila empregando o expansor tipo Haas modificado pode ser considerada um procedimento biologicamente seguro para o complexo dentinopulpar.

Deve-se ressaltar que as forças empregadas na expansão rápida da maxila devem ser suficientemente intensas para hialinizar o ligamento periodontal vestibular, para que não ocorra a movimentação dentária. Mesmo assim não foram observadas alterações pulpares do ponto de vista microscópico.

Em 2005, orientamos o trabalho de mestrado 
de Renata B. Consolaro ${ }^{1}$, no qual foram movimentados dentes de 39 ratos em períodos de 1 a 7 dias, utilizando-se o modelo inicialmente desenvolvido por Heller e Nanda ${ }^{2}$, com aprimoramentos desenvolvidos por Martins-Ortiz ${ }^{3}$, reconhecido mundialmente por ser o mais utilizado nos trabalhos sobre o assunto. Analisamos os tecidos pulpares comparando-os com os de dentes não movimentados de outros 9 animais. Verificamos e concluimos que a movimentação dentária induzida não promoveu alterações morfológicas na polpa dentária detectáveis na microscopia óptica, quer sejam de natureza degenerativa, quer sejam de natureza inflamatória.

Apesar destes trabalhos, ainda muitos acreditam que o tratamento ortodôntico possa provocar necrose pulpar, envelhecimento precoce e até escurecimento dentário por obliteração pulpar decorrente de uma metaplasia dos tecidos pulpares, conhecida como Metamorfose Cálcica da Polpa. Acreditam, mas a literatura e os poucos trabalhos revelam que esta possibilidade praticamente não existe.

O envelhecimento pulpar decorre da perda de celularidade pulpar resultante do fechamento gradual com a idade do forame apical, que reduz a nutrição celular, causando hialinização, fibrosamento pulpar e estabelecimento de nódulos pulpares. Estão associados ao envelhecimento pulpar precoce: os desgastes dentários, abfração, procedimentos restauradores, estéticos e cáries dentárias. Os pequenos traumatismos podem diminuir parcial e transitoriamente a nutrição pulpar e contribuir com o envelhecimento pulpar precoce. Não devemos considerar a movimentação dentária como pequenos traumatismos?

A movimentação dentária ortodonticamente obtida não é brusca, à força, quando mais intensa, ainda assim não produz movimentos rápidos que justifiquem lesão ou rompimento dos vasos sanguíneos na porção apical, embora possa aumentar muito discretamente o volume sanguíneo pulpar nas primeiras $6 h^{4}$. A lesão ou rompimento dos feixes vasculares apicais estão associados com o traumatismo dentário indutor de movimentos dentários repentinos, bruscos, intensos, pelos deslocamentos intra-alveolares induzidos.

Quando a polpa dentária tem seus vasos sanguíneos lesados, mas não rompidos, ou seja, comprimidos,
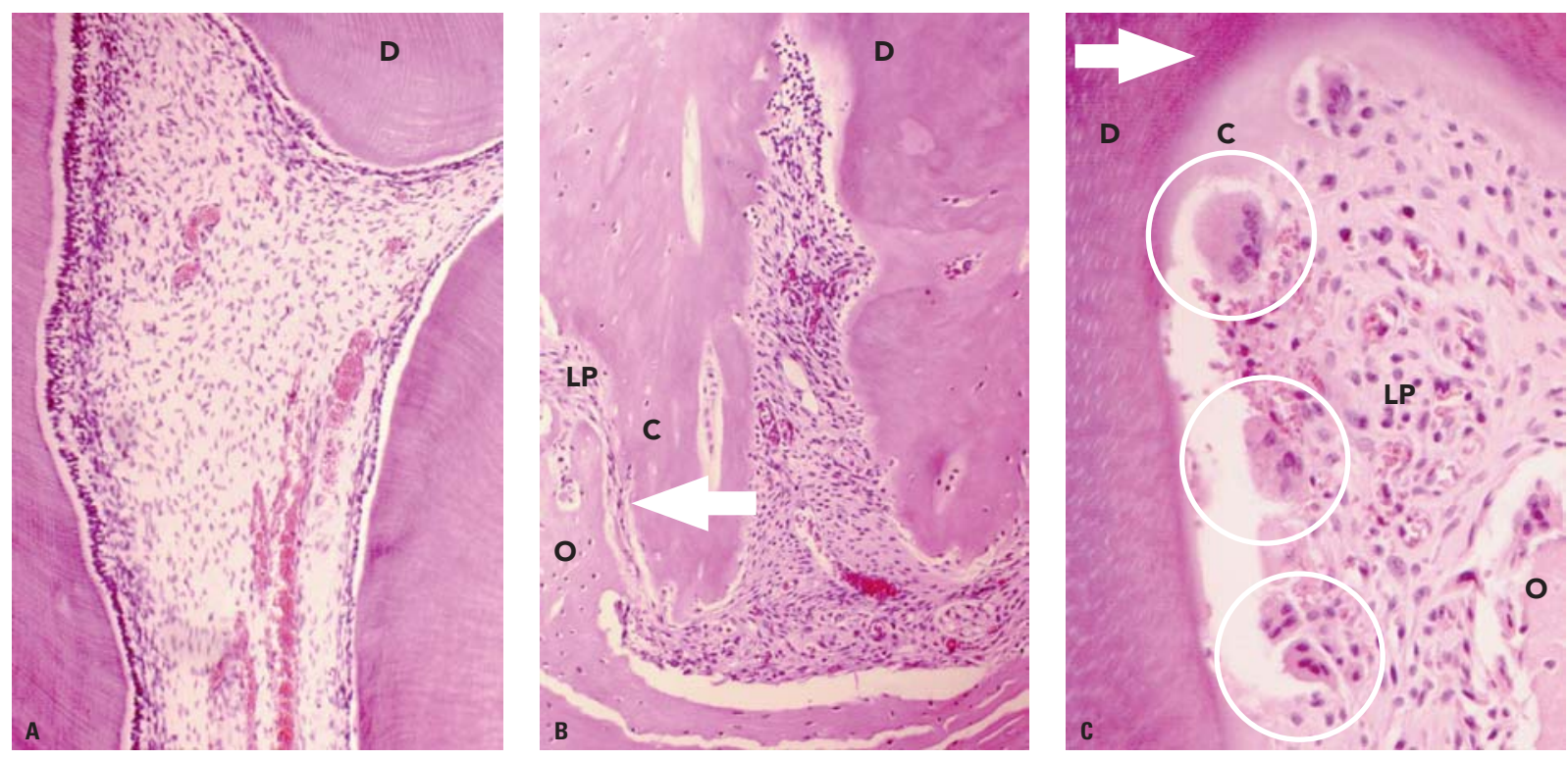

FIGURA 1 - Aspectos microscópicos da polpa coronária (A) e apical (B) de dente murino submetido a forças (setas) durante 7 dias. A polpa está morfologicamente normal. Em B, o ligamento periodontal está comprimido. Em C, na superfície radicular do mesmo dente, região cervical, nota-se que os cementoblastos foram eliminados e no local instalaram-se várias BMUs, ou unidades osteorremodeladoras (ćŕrculos), que eliminaram o cemento e reabsorvem a dentina, indicando que a força experimental foi eficaz. $\mathbf{D}=$ dentina, LP=ligamento periodontal, $\mathbf{C}=$ cemento, $\mathbf{0}=0$ sso alveolar. (Fonte: MARTINS-0RTIZ, 2004; CONSOLARO, R., 2005) 
rompidos parcial ou transitoriamente, as suas células podem entrar em intenso estresse, que causa a mudança de seu fenótipo para se adaptarem à nova situação metabólica. Esta mudança de fenótipo, e de função também, é denominada metaplasia e na polpa leva à obliteração pulpar da câmara pulpar e/ou do canal radicular, pois quase todas as células da polpa se transformam em odontoblastos-like. Simultaneamente haverá produção aleatória de dentina displásica, respeitando os vasos e nervos, mas radiograficamente com completa obliteração do espaço pulpar coronário e/ou radicular. Às vezes, esta dentina também é referida como osteodentina ou vaso-dentina. Ao longo dos anos a polpa pode necrosar, inclusive com lesões periapicais crônicas. Esta situação promove o escurecimento gradativo do dente traumatizado ao longo de meses e anos e é referida como Metamorfose Cálcica da Polpa. Infelizmente, muitos acreditam, por crença ou fé, que o tratamento ortodôntico possa provocar tal situação.

Os objetivos do Insight Ortodôntico estão focados no questionamento constante, na indução a novas buscas a partir de inquietações apontadas e na análise de novas idéias. Sobre este assunto, têmse as seguintes premissas:

1) o envelhecimento pulpar pode ser analisado imaginologicamente em radiografias periapicais e tomografias odontológicas;

2) o número de pacientes atendidos na prática clínica ortodôntica é muito grande;

3) os pacientes têm radiografias periapicais antes, durante e depois do tratamento ortodôntico com possibilidade de controles anuais;

\section{REFERÊNCIAS}

1. CONSOLARO, Renata B. Análise do complexo dentinopulpar em dentes submetidos à movimentação dentária induzida em ratos. 2005. 125 f. Dissertação (Mestrado)-Universidade de São Paulo, Faculdade de Odontologia de Bauru, Bauru, 2005

2. HELLER, I. J.; NANDA, R. Effect of metabolic alteration of periodontal fibers on orthodontic tooth movement. An experimenta study. Am J Orthod, St. Louis, v. 75, no. 3, p. 239-258, Mar. 1979.

3. MARTINS-ORTIZ, M. F. Influência dos bisfosfonatos na movi-
4) as variáveis técnicas, de intensidade de forças e de tipos de movimento permitem comparações entre tipos de procedimentos;

5) muitos dentes são extraídos por indicação ortodôntica, possibilitando análise microscópica da polpa em muitos casos, sem infringir aspectos éticos;

6) ainda muitos casos de envelhecimento pulpar precoce, metamorfose cálcica da polpa ou necrose pulpar são atribuídos ao tratamento ortodôntico.

Se considerarmos estas premissas, surge um questionamento importante: por que a Ortodontia não pesquisa mais intensamente os efeitos pulpares da movimentação dentária induzida? Seria por respeito a um velho dogma?

A espessura do ligamento periodontal, em média, é de $0,25 \mathrm{~mm}$. No terço apical a deflexão óssea é insignificante. $O$ tecido conjuntivo é elástico e próprio para preenchimento de espaços em nosso organismo. A força ortodôntica não é bruscamente aplicada. Não há bases anatômicas e fisiopatológicas para explicar as alterações pulpares induzidas pela movimentação ortodôntica a partir de alterações vasculares apicais.

Quantos pacientes adultos, anos depois do tratamento ortodôntico realizado, se apresentam com polpas diminuídas em seu espaço radiográfico, com múltiplos nódulos pulpares e alguns dentes com obliteração total da polpa coronária e/ou do canal radicular?

Vamos aos dados para verificar estes achados clínicos, sempre com muito critério na constituição das amostras e rigor nas análises!

mentação dentária induzida, na freqüência e nas dimensões das reabsorções radiculares associadas. 2004. $188 \mathrm{f}$. Tese (Doutorado)-Faculdade de Odontologia de Bauru, Universidade de São Paulo, Bauru, 2004

4. SANTAMARIA JR., M. et al. Initial changes in pulpar microvasculature during orthodontic tooth movement: a stereological study. Eur J Orthod, Oxford, v. 28, p. 217-220, 2006.

5. VALADARES NETO, J. Análise microscópica do complexo dentinopulpar e da superfície radicular externa após a expansão rápida da maxila em adolescentes. 2000. 196 f. Dissertação (Mestrado)-Instituto de Ciências Biológicas, Universidade Federal de Goiás, Goiânia, 2000 